percentagem de estande em híbridos simples de milho $s h-2$ variam de $38 \%$ a $66 \%$ em condições de campo.

\section{LITERATURA CITADA}

ALEXANDER, D.E.; CREECH, R.G. Breeding special industrial and nutritional types. In: SPRAGUE, G.F. ed. Corn and corn improvement. American Society of Agronomy, Inc. Publisher, Madison, Wisconsin, USA, 1977. p. 363-390.

ALLARD, R.W. Princípios de melhoramento genético das plantas. São Paulo: Edgar Blucher, $1971.381 \mathrm{p}$.

ANDREW, R.H. Factors influencing early seeding vigor of shrunken-2 maize. Crop Science, v. 22, n. 2, p. 263-266, 1982.

BELL, R.D.; DARRAH, L.L.; ZUBER, M.S. Progress from mass selection for field emergence and seed weight in a $s h-2$ population of maize. Crop Science, v. 23, n. 3, p. 461-464, 1983.
BOROWSKI, A.M.; VICENTE, A.F.; WATERS JR., L. Seed maturity influences germination and vigor of two shrunken-2 sweet corn hybrids. Journal America Society Horticultural Science, v. 116, n. 3, p. 401-404, 1991.

GRIFFING, B. Concept of general and specific combining ability in relation to diallel crossing systems. Australian Journal of Biological Sciences, v. 9, n. 4, p. 463-493, 1956.

HANNAH, L.C.; CANTLIFFE, D.J. Percentage stand and sugars in four Florida sweet corns. Proceeding of the Florida State Horticultural Society, v. 90, p. 412-413, 1978.

LAUGHMAN, J.R. The effect of the $s h-2$ factor on carbohydrate reserves in the mature endosperm of maize. Genetics, v. 38, n. 5, p. 485-499, 1953. PAINI, J.N.; CRUZ, C.D.; DELBONI, J.S.; SCAPIM, C.A. Capacidade combinatória e heterose em cruzamentos intervarietais de milho avaliados sob as condições climáticas da região sul do Brasil. Revista Ceres, Viçosa, v. 43, n. 247, p. 288-300, 1996.
SCAPIM, C.A. Cruzamentos dialélicos entre sete variedades de milho doce e correlações entre caracteres agronômicos, Viçosa, 1994. 96 p. (Tese mestrado).

STYER, R.C.; CANTLIFFE, D.J. Relationship between environment during seed development and seed vigor of two endosperm mutants of corn. Journal of the America Society for Agricultural Science, v. 108, n. 5, p. 717-720, 1983.

STYER, R.C.; CANTLIFFE, D.J. Dependence of seed vigor during germination on carbohydrate source in endosperm mutants of maize. Plant Physiology, v. 76, n. 1, p. 196-200. 1984.

SPRAGUE, G.F.; TATUM, L.A. General vs. specific combining ability in single crosses of corn. Journal of the American Society of Agronomy, v. 34, n. 10, p. 923-932, 1942.

TRACY, W.F. Sweet corn. In: HALLAUEER, A.R. Specialty corns. New York, CRC Press, Boca Raton, 1994. p. 148-187.

VENCOVSKY, R.; BARRIGA, P. Genética e biométrica no fitomelhoramento. Ribeirão Preto, Revista Brasileira de Genética, 1992. 486 p.

NEGREIROS, M.Z.; BEZERRA NETO, F.; PORTO, V.C.N.; SANTOS, R.H.S. Cultivares de alface em sistemas solteiro e consorciado com cenoura em Mossoró. Horticultura Brasileira, Brasília, v. 20, n. 2, p. 162-166, junho 2.002.

\title{
Cultivares de alface em sistemas solteiro e consorciado com cenoura em Mossoró
}

\author{
Maria Z. de Negreiros ${ }^{1}$; Francisco Bezerra Neto ${ }^{1}$ Vânia C. N. Porto' ${ }^{1}$ Ricardo H. S. Santos ${ }^{2}$ \\ ${ }^{1}$ ESAM, Dept ${ }^{\mathrm{o}}$ de Fitotecnia C. Postal 137, 59.625-900, Mossoró - RN; ${ }^{2}$ UFV, Dept ${ }^{\mathrm{o}}$ de Fitotecnia, 36.571-000 Viçosa - MG. E-mail: \\ zuleide@esam.br.
}

\section{RESUMO}

O experimento foi conduzido de dezembro/97 a março/98 na ESAM. Avaliou-se o desempenho de cinco cultivares de alface em dois sistemas de cultivo (solteiro e consorciado) com a cultivar de cenoura Brasília, bem como a performance da cenoura nestes sistemas de cultivo, nas condições de temperatura elevada e ampla luminosidade de Mossoró (RN). O solo foi Argissolo Vermelho Amarelo Eutrófico. O delineamento experimental foi de blocos casualizados completos com cinco repetições, em esquema fatorial $2 \times 5$. O primeiro fator foi constituído dos sistemas de cultivo (solteiro e consorciado), e o segundo fator das cultivares de alface (Babá de Verão, Elisa, Great Lakes, Regina e Tainá). Em cada bloco foi plantada uma parcela solteira de cenoura, para obtenção dos índices combinados. Duas análises de variância univariadas foram realizadas: uma para avaliar as características da alface no fatorial $2 \times 5$ e a outra para as características da cenoura em blocos casualizados com seis tratamentos, provenientes das cinco cultivares de alface consorciadas com a cenoura, além da cenoura em sistema solteiro. As culturas tiveram produções adequadas para a comercialização, em ambos os sistemas de cultivos avaliados. Independentemente destes sistemas, a maior produtividade de alface foi observada na cultivar Babá de Verão. O sistema consorciado cenoura e alface "Regina" foi o mais viável agroeconomicamente (com índice de uso da terra em torno de 16\%). Os rendimentos de raízes da cenoura não foram afetados pela competição das cultivares de alface estudadas.

Palavras-chave: Lactuca sativa, Daucus carota, consórcio, índices agroeconômico, sistemas de cultivo.

\begin{abstract}
Performance of lettuce cultivars with and without intercropping with carrot in Mossoró

An experiment was carried out between December 1997 and March 1998, in the Escola Superior de Agricultura de Mossoró, Brazil, to evaluate the performance of five lettuce cultivars in two cropping systems (with and without intercropping with the carrot cv. Brasília) as well as the performance of carrot treatments in these cropping systems, under high temperature and ample sunlight of Mossoró. This experiment was carried out in an Eutrophic Yellow Red Argissolo. The experimental design was of randomized complete blocks in a $2 \times 5$ factorial scheme with five replications. The planting systems were the first factor and the lettuce cv. (Babá de Verão, Elisa, Great Lakes, Regina and Tainá) were the second factor. There was, in each block, a plot with carrot without intercropping to assess the combined indices of the intercropping systems. Two types of univariate analyses of variance were performed, one to evaluate the lettuce traits and another for the carrot characteristics. Crop production was considered suitable for the marketing. Independently of the cropping system used, higher lettuce yield was observed in the cultivar Babá de Verão. The intercropping system which gave the best economic performance and greater land equivalent ratio (1.16) was carrot plus cultivar Regina. Carrot root yield was not affected by the competition of lettuce cultivars.
\end{abstract}

Keywords: Lactuca sativa, Daucus carota, intercropping, agroeconomic index, cropping systems. 
O consórcio de culturas é prática tradicional de produção de alimentos e biomassa nas regiões tropicais, onde pequenas propriedades e operações intensivas predominam. No trópico semi-árido do Nordeste brasileiro esta prática tem sido uma das formas de aumento da produção de culturas entre os pequenos agricultores (Bezerra Neto et al., 1991; Bezerra Neto \& Robichaux, 1996, Bezerra Neto \& Robichaux, 1997). Nestas associações de culturas, o objetivo tem sido o de maximizar a utilização dos recursos ambientais e da área, além da mão-deobra nas diversas operações com aplicação de insumos e tratos culturais.

Os sistemas de cultivo, com associações de culturas envolvendo hortaliças têm sido pouco estudados nas condições semi-áridas do Nordeste do Brasil, principalmente aquelas envolvendo cenoura e alface. Nenhum trabalho foi realizado em relação ao potencial de cultivares de alface no consórcio com cenoura sob condições de alta temperatura e ampla luminosidade. As cultivares de alface disponíveis foram selecionadas visando o monocultivo, não sendo possível prever o comportamento de genótipos em consórcio a partir dos resultados obtidos com cultivares isoladas. Caetano et al. (1999), trabalhando com cultivares de alface em consórcio com cenoura e em cultivo solteiro nas condições do Rio de Janeiro, verificaram comportamento diferenciado entre as cultivares nos dois sistemas estudados com uma vantagem de mais de $70 \%$ no uso da terra no sistema consorciado. Por outro lado, em experimento conduzido na Universidade da Pennsylvania com o consórcio cenoura $\mathrm{x}$ milho doce, foi observado que este sistema de cultivo aumentou o rendimento combinado destas hortaliças e que o peso fresco das raízes de alguns tratamentos consorciados da cenoura foi reduzido (Ogbuehi \& Orzolek, 1987).

Sabe-se que a alface é hortaliça originária de clima temperado e sua adaptação, em temperatura elevada, tem gerado obstáculos ao seu crescimento e desenvolvimento, impedindo que a cultura expresse todo o seu potencial genético. Nestas condições, ocorre redução do ciclo da cultura comprometendo sua produção, devido à antecipação da fase reprodutiva (Setúbal \& Silva,1992;
Makishima, 1992). Porém, o uso de práticas culturais como cobertura morta e sombreamento pode contribuir para o alongamento do ciclo vegetativo, melhoria da qualidade do produto e aumento da produtividade.

O objetivo deste trabalho foi avaliar o desempenho de cinco cultivares de alface em sistemas de cultivo solteiro e consorciado com a cultivar de cenoura Brasília, bem como a performance da cenoura nas condições de temperatura elevada e ampla luminosidade de Mossoró-RN.

\section{MATERIAL E MÉTODOS}

O experimento foi conduzido na ESAM, de dezembro/97 a março/98, em Argissolo Vermelho Amarelo Eutrófico. Da área experimental, foram retiradas amostras, cuja análise resultou: $\mathrm{pH}$ (água 1:2,5) =7,1; $\mathrm{Ca}=4,87{\mathrm{cmolc} \mathrm{dm}^{-}}^{-}$ 3; $\mathrm{Mg}=1,35 \mathrm{cmolc} \mathrm{dm}^{-3} ; \mathrm{K}=0,45$ cmolc $\mathrm{dm}^{-3} ; \mathrm{Na}=0,24 \mathrm{cmolc} \mathrm{dm}^{-3} ; \mathrm{Al}=0,00$ cmolc dm $\mathrm{dm}^{-3}$ e $\mathrm{P}=182 \mathrm{mg} \mathrm{dm}^{-3}$.

O delineamento experimental foi de blocos casualizados completos com cinco repetições, em esquema fatorial $2 \mathrm{x}$ 5 , compreendendo dois sistemas de cultivo (solteiro e consorciado com a cultivar de cenoura Brasília, em fileiras alternadas) e cinco cultivares de alface (Babá de Verão, Elisa, Great Lakes, Regina e Tainá). Em cada bloco foi plantada uma parcela solteira de cenoura, para obtenção dos índices combinados. As parcelas tinham uma área total de $1,20 \mathrm{~m}^{2}$, sendo que para o sistema solteiro de alface a área útil da parcela foi de $0,48 \mathrm{~m}^{2}$, contendo 12 plantas no espaçamento de $0,20 \mathrm{~m}$ x $0,20 \mathrm{~m}$, e no sistema solteiro de cenoura a área útil foi de $0,64 \mathrm{~m}^{2}$, com 32 plantas espaçadas de 0,20 m x 0,10 m. No sistema de cultivo consorciado, a área útil da parcela foi de $0,64 \mathrm{~m}^{2}$, contendo 16 plantas de alface e 32 de cenoura. Nesse sistema, o espaçamento da alface foi de 0,40 $\mathrm{m} \times 0,10 \mathrm{~m}$ e da cenoura $0,40 \mathrm{~m} \times 0,05$ $\mathrm{m}$, correspondendo, respectivamente, a 250.000 e 500.000 plantas por hectare, as mesmas densidades utilizadas no sistema solteiro.

As cultivares de alface foram semeadas em janeiro/98 em bandejas de isopor com 128 células, utilizando-se como substrato uma mistura de húmus e vermiculita na proporção de $2: 1$ respectivamente. A partir da emergência até o dia do transplante as mudas foram sombreadas com tela de nylon, cor preta de malha $2 \times 2 \mathrm{~mm}$, colocada a $25 \mathrm{~cm}$ de altura do leito da sementeira. O transplante das mudas foi realizado aos quatorze dias após a semeadura, quando as mesmas apresentavam de três a quatro folhas definitivas. Nos cultivos solteiro e consorciado, as mudas de alface foram transplantadas quando a cultura da cenoura estava com 60 dias após o plantio.

A cenoura foi semeada em dezembro/97, em covas espaçadas de 0,05 e $0,10 \mathrm{~m}$, respectivamente, nas parcelas consorciada e solteira. $\mathrm{O}$ desbaste foi realizado aos 22 dias após a semeadura deixando-se uma planta/cova.

A colheita foi realizada em março/98, sendo que a cenoura foi colhida aos 90 dias e a alface 45 dias após a semeadura.

Para a cultura da alface foram avaliados o número de folhas por planta, altura e diâmetro de plantas, matéria seca da parte aérea e a produtividade comercial. Da cultura da cenoura foram avaliadas a altura de plantas, matérias fresca e seca da parte aérea, matéria seca de raízes e a produtividade comercial. Alguns índices agroeconômicos foram usados para medir a eficiência dos sistemas consorciados (Beltrão et al. 1984): índice de uso eficiente da terra (UET), agressividade (A), renda bruta $(\mathrm{RB})$, renda líquida (RL), vantagem monetária $(\mathrm{VM})$, vantagem monetária corrigida (VMc) e taxa de retorno (TR). $\mathrm{O}$ índice UET é dado pela expressão: $\left(\mathrm{I}_{\text {cenoura }} / \mathrm{S}_{\text {cenoura }}\right)+\left(\mathrm{I}_{\text {alface }} / \mathrm{S}_{\text {alface }}\right)$, onde I e S representam os rendimentos dos sistemas consorciado e solteiro de cada cultura componente. A agressividade foi obtida pela expressão: $A_{c a}=\left(Y_{c a} / Y_{c c} x\right.$ $\left.Z_{c a}\right)-\left(Y_{a c} / Y_{a a} \times Z_{a c}\right)$, onde $A_{c a}$ é o índice de agressividade da cenoura ' $c$ ' sobre a alface ' $a$ '; $Y_{\text {ca }}$ é o rendimento da cenoura consorciada com a alface; $\mathrm{Y}_{\mathrm{cc}}$ é o rendimento da cenoura solteira; $Z_{c a}$ é a proporção de plantio da cenoura consorciada com alface; $\mathrm{Y}_{\mathrm{ac}}$ é o rendimento da alface consorciada com a cenoura; $\mathrm{Y}_{\mathrm{aa}}$ é o rendimento da alface solteira e $\mathrm{Z}_{\mathrm{ac}}$ é a proporção de plantio da alface consorciada com a cenoura. 
Tabela 1. Número de folhas por planta de cinco cultivares de alface nos sistemas de cultivo solteiro e consorciado. Mossoró, ESAM, 1998.

\begin{tabular}{lcrc}
\hline \multirow{2}{*}{ Cultivares } & \multicolumn{2}{c}{ Sistemas de cultivo } & \multirow{2}{*}{ Consórcio/solteiro } \\
\cline { 2 - 3 } & Solteiro & Consorciado & 40 \\
Babá de Verão & $26,76 \mathrm{Aa} *$ & $10,68 \mathrm{Ba}$ & 36 \\
Elisa & $24,56 \mathrm{Aa}$ & $8,78 \mathrm{Ba}$ & 48 \\
Great Lakes & $12,58 \mathrm{Ab}$ & $5,98 \mathrm{Bb}$ & 45 \\
Regina & $24,84 \mathrm{Aa}$ & $11,30 \mathrm{Ba}$ & 46 \\
Tainá & $12,90 \mathrm{Ab}$ & $5,98 \mathrm{Bb}$ & 45 \\
\hline
\end{tabular}

${ }^{*}$ Médias seguidas pelas letras maiúsculas diferentes nas linhas diferem entre si pelo teste $\mathrm{F}$ e seguidas pelas mesmas letras minúsculas nas colunas não diferem entre si pelo teste de Tukey a $5 \%$ de probabilidade.

A renda bruta foi obtida multiplicando-se a produtividade da cultura em cada tratamento pelo valor do produto, pago ao produtor no mês de fevereiro/99. A renda líquida foi calculada subtraindose da renda bruta, os custos de produção, provenientes de insumos mais serviços. Estes custos foram calculados para cada tratamento, baseado nos coeficientes de custo de insumos e serviços utilizados em um hectare de cenoura e alface a nível experimental. Foram considerados os preços de insumos e serviços vigentes no mês de fevereiro/99, na cidade de Mossoró. A vantagem monetária e a vantagem monetária corrigida foram obtidas pelas seguintes expressões: VM = RB x (UET -1)/UET e VMc $=\mathrm{RL} \times(\mathrm{UET}-1) / \mathrm{UET}$. A taxa de retorno por real investido em cada tratamento foi obtida por meio da relação entre a renda bruta e o custo de produção de cada tratamento.

Duas análises de variância univariadas foram usadas: uma para avaliar as características da alface no delineamento em blocos casualizados em esquema fatorial $2 \times 5$ (provenientes de dois sistemas de cultivo e cinco cultivares de alface) e a outra para as características da cenoura em blocos casualizados com seis tratamentos (provenientes de cinco cultivares de alface consorciadas com a cenoura além da cenoura solteira).

\section{RESULTADOS E DISCUSSÃO}

A interação entre sistemas de cultivo e cultivares no número de folhas de alface por planta foi significativa. Desdobrando esta interação, observou-se que as cultivares de alface tiveram com- portamento diferenciado dentro de cada sistema de cultivo, com a Babá de Verão, Regina e Elisa registrando maior número de folhas por planta em ambos os sistemas (Tabela 1). No entanto, nas cultivares Great Lakes, Tainá e Regina foram observadas menores perdas do potencial do número de folhas $(48 \%$, $46 \%$ e $45 \%$, respectivamente) do que nas cultivares Babá de Verão e Elisa (40\% e 36\%). Observou-se também maior número de folhas de alface por planta no sistema solteiro dentro de cada cultivar estudada (Tabela 1). Isto se deve, provavelmente, a uma maior competição interespecífica sofrida pelas plantas de alface no sistema consorciado. Este resultado concorda em parte, com os obtidos por Carneiro (1981) e Bezerra Neto (1993), trabalhando com outros tipos de consórcio.

Para a característica altura de plantas de alface, verificou-se efeito significativo apenas de cultivares, e para diâmetro de plantas constataram-se efeitos de sistemas de cultivo e cultivares. A cultivar Babá de Verão sobressaiu-se das demais em termos de altura $(12,17$ $\mathrm{cm})$ e diâmetro $(17,02 \mathrm{~cm})$ de plantas (Tabela 2). Com relação aos sistemas de cultivo, a alface consorciada registrou menor diâmetro de plantas $(11,67 \mathrm{~cm})$ quando comparada com a solteira $(16,85$ $\mathrm{cm})$. Este resultado, provavelmente se deve, ao maior adensamento das plantas de alface dentro da linha de plantio no sistema consorciado, promovendo maior competição intraespecifica, além da competição entre as culturas, principalmente com relação à radiação solar, devido ao sombreamento exercido pela cenoura sobre a alface, pois a mesma foi transplantada quando a cenoura es- tava com sessenta dias. Segundo Ofori \& Stern (1987), quando uma planta alta sombreia uma mais baixa, a competição estabelecida entre ambas, causa diminuição no crescimento e desenvolvimento da planta menor.

Para a matéria seca da parte aérea e produtividade de alface observaram-se efeitos significativos de sistemas de cultivo e de cultivares de alface. Menor produção de matéria seca e menor produtividade foram registradas na alface em cultivo consorciado quando comparada com aquela do sistema solteiro (Tabela 2). Este resultado discorda em parte, daqueles de Caetano et al (1999), onde encontraram produtividade mais elevada no consórcio do que no cultivo solteiro.

A cultivar Babá de Verão sobressaiuse das demais em relação à produção de matéria seca $(0,50 \mathrm{t} / \mathrm{ha})$ e a produtividade $(7,30 \mathrm{t} / \mathrm{ha})$. A cultivar Regina registrou seus menores valores, $0,21 \mathrm{e}$ 2,76 t/ha, respectivamente (Tabela 2). Estes resultados discordam em parte dos obtidos por Caetano et al. (1999) em um dos ensaios realizados em Campo dos Goytacazes, onde encontraram resultados opostos em termos de produtividade da alface.

Com relação às características avaliadas na cenoura, não foram observadas diferenças significativas entre os sistemas de cultivo avaliados. Isto evidencia que as diferentes pressões de competição exercidas pelas cultivares de alface na cenoura não foram suficientes para diferenciá-los. Estes resultados discordam dos encontrados por Caetano et al. (1999), em um dos ensaios realizados em Campo dos Goytacazes, onde encontraram efeito da cultivar de alface Marisa na produtividade da cenoura. 
Tabela 2. Valores médios de altura e diâmetro de plantas, matéria seca da parte aérea e produtividade obtidos nos cultivos solteiro e consorciado e nas cinco cultivares de alface. Mossoró, ESAM, 1998.

\begin{tabular}{lcccc}
\hline $\begin{array}{c}\text { Sistemas } \\
\text { de Cultivo }\end{array}$ & $\begin{array}{c}\text { Altura de plantas } \\
(\mathbf{c m})\end{array}$ & $\begin{array}{c}\text { Diâmetro de plantas } \\
(\mathbf{c m})\end{array}$ & $\begin{array}{c}\text { Matéria seca da } \\
\text { parte aérea (t/ha) }\end{array}$ & Produtividade(t/ha) \\
\hline Solteiro & 10,81 & $16,85 \mathrm{~A}$ & $0,57 \mathrm{~A}$ & $8,10 \mathrm{~A}^{*}$ \\
Consorciado & 9,88 & $11,67 \mathrm{~B}$ & $0,09 \mathrm{~B}$ & $1,22 \mathrm{~B}$ \\
\hline Cultivares & \multicolumn{5}{l}{} & \\
\hline Babá de Verão & $12,17 \mathrm{a}$ & $17,02 \mathrm{a}$ & $0,50 \mathrm{a}$ & $7,30 \mathrm{a}$ \\
Elisa & $9,69 \mathrm{ab}$ & $13,69 \mathrm{~b}$ & $0,27 \mathrm{ab}$ & $4,00 \mathrm{ab}$ \\
Great Lakes & $10,55 \mathrm{ab}$ & $13,35 \mathrm{~b}$ & $0,30 \mathrm{ab}$ & $3,73 \mathrm{ab}$ \\
Regina & $9,22 \mathrm{~b}$ & $13,27 \mathrm{~b}$ & $0,21 \mathrm{~b}$ & $2,76 \mathrm{~b}$ \\
Tainá & $10,09 \mathrm{ab}$ & $13,99 \mathrm{ab}$ & $0,36 \mathrm{ab}$ & $5,52 \mathrm{ab}$ \\
\hline
\end{tabular}

${ }^{*}$ Médias na coluna seguida de letra maiúscula diferente diferem entre si pelo teste $\mathrm{F}$ e de mesma letra minúscula não diferem entre si pelo teste de Tukey a $5 \%$ de probabilidade.

Tabela 3. Índice de uso eficiente da terra, agressividade, renda bruta, renda líquida, vantagem monetária, vantagem monetária corrigida e taxa de retorno da cenoura nos sistemas de cultivo consorciado e solteiro. Mossoró, ESAM, 1999.

\begin{tabular}{|c|c|c|c|c|c|c|c|}
\hline Sistemas de Cultivo & UET & $A c \rightarrow a$ & RB (R\$/ha) & RL (R\$/ha) & VM (R\$/ha) & $\begin{array}{c}\text { VMc } \\
\text { (R\$/ha) }\end{array}$ & TR \\
\hline Cenoura + Babá de Verão & 1,01 & 0,72 & 20170,00 & 15970,00 & 199,7 & 158,1 & 4,80 \\
\hline Cenoura + Elisa & 0,86 & 0,66 & 16752,00 & 12552,00 & 2727,0 & $-2043,3$ & 3,99 \\
\hline Cenoura + Great Lakes & 0,92 & 0,66 & 17612,00 & 13412,00 & 1531,4 & $-1166,2$ & 4,19 \\
\hline Cenoura + Regina & 1,16 & 0,61 & 20350,00 & 16150,00 & 2806,9 & 2227,5 & 4,84 \\
\hline Cenoura + Tainá & 0,95 & 0,65 & 18490,00 & 14290,00 & $-973,1$ & $-752,1$ & 4,40 \\
\hline Cenoura (Solteiro) & 1,00 & & 21560,00 & 17360,00 & & & 5,13 \\
\hline
\end{tabular}

No geral, a produtividade da cenoura variou de cerca de 22 a $29 \mathrm{t} / \mathrm{ha}$, nos sistemas de cultivo consorciado e solteiro, respectivamente. Estas produtividades estão próximas à média da região Nordeste, que é de $25 \mathrm{t} / \mathrm{ha}$ (Vilela et al., 1997). Em termos comerciais, observouse boa qualidade de raízes da cenoura, com pequena quantidade fora do padrão (refugo), apesar de ter sido classificada na faixa de 9 a $12 \mathrm{~cm}$ de comprimento e de 1,0 a 2,5 cm de diâmetro, que segundo as Normas do Ministério da Agricultura está enquadrada na classe curta.

Avaliações dos índices combinados (UET e agressividade) e dos indicadores econômicos $\left(\mathrm{RB}, \mathrm{RL}, \mathrm{VM}, \mathrm{VM}_{\mathrm{c}} \mathrm{e}\right.$ TR) foram utilizadas para determinar se havia alguma vantagem no consórcio com relação ao uso da terra e ao retorno monetário (Tabela 3). Convém ressaltar, que não foi possível realizar análise de variância para estes índices e indicadores, em virtude das hipóteses da normalidade e da homogeneidade não te- rem sido encontradas.

Verificou-se que dois sistemas registraram índices de uso da terra (UET) maiores do que a unidade, ou seja, quando a cenoura estava consorciada com a cultivar de alface Babá de Verão (registrando uma eficiência de $1 \%$ ) e com a cultivar Regina (apresentando uma eficiência de 16\%). Estes resultados concordam em parte com os obtidos por Caetano et al. (1999) em outras condições de manejo e ambiente, onde obtiveram vantagens de $74 \%$ e $106 \%$ no uso da terra, com estas duas cultivares de alface consorciada com cenoura em um dos ensaios realizado no Rio de Janeiro.

Com relação ao índice de agressividade (A), pode-se observar que a cenoura é a cultura dominante, pois em todos os sistemas consorciados este índice teve valor positivo. No sistema cenoura + Regina foi observado menor valor $(0,61)$ deste índice (Tabela 3$)$.

O sistema consorciado cenoura + Regina (com maior valor de UET, 16\%) foi o que teve as maiores rendas bruta $\mathrm{e}$ líquida e taxa de retorno, em torno de $\mathrm{R} \$$ $20.350,00, \mathrm{R} \$ 15.970,00$ e 4,84, respectivamente, um pouco abaixo das rendas e taxa de retorno do cultivo solteiro da cenoura (Tabela 3). Vale salientar que a renda líquida é um indicador que expressa melhor o valor dos sistemas do que a renda bruta, pois nela está deduzido o custo de produção (insumos + serviços).

$\mathrm{O}$ índice de vantagem monetária (VM) que depende da UET e da renda bruta foi de $\mathrm{R} \$ 2.806,90$ para cenoura + Regina (Tabela 3). De igual modo, a vantagem monetária corrigida (VMc) que é baseada na renda líquida (RL), foi de R $\$ 2.227,50$ para este sistema. Estes resultados expressam a vantagem do uso eficiente da terra em termos monetário. Como se pode observar, não houve disparidade entre a UET e a VM no melhor sistema, indicando que uma vantagem agronômica garantiu também por sua vez uma vantagem econômica no sistema consorciado. 
De modo geral, as culturas tiveram produções adequadas para a comercialização em ambos os sistemas de cultivo avaliados. Independente destes sistemas, a maior produtividade de alface foi obtida pela cultivar Babá de Verão. Os rendimentos de raízes da cenoura não foram afetados pela competição das cultivares de alface estudadas. Em termos de índices combinados e de indicadores econômicos, o sistema consorciado cenoura + cultivar de alface Regina foi o que se mostrou mais viável.

\section{LITERATURA CITADA}

BELTRÃO, N.E.M. Comparação entre indicadores agroeconômicos de avaliação de agroecossistemas consorciados e solteiros envolvendo algodão "upland" e feijão "caupi". Campina Grande: EMBRAPACNPA, 1984. 21 p. (EMBRAPA-CNPA. Boletim de Pesquisa, 15).

BEZERRA NETO, F. Effects of spatial arrangement and density on efficiency, yield and yield components, dry matter partitioning and growth of an annual cotton/ cowpea/maize intercrop. Tucson, Arizona: University of Arizona, 1993. 164 p. (Tese doutorado).
BEZERRA NETO, F.; ROBICHAUX, R.H. Spatial arrangement and density effects on an annual cotton/cowpea/maize intercrop. I. Agronomic efficiency. Pesquisa Agropecuária Brasileira, Brasília, v. 31, n. 10, p. 729-741, 1996.

BEZERRA NETO, F.; ROBICHAUX, R.H. Spatial arrangement and density effects on an annual cotton/cowpea/maize intercrop. II. Yield and biomass. Pesquisa Agropecuária Brasileira, Brasília, v. 32, n. 10, p. 1029 1037, 1997.

BEZERRA NETO, F; TORRES FILHO, J.; HOLANDA, J.S.; SANTOS, E.F.; ROSADO, C.A.S. Efeito do sistema de cultivo e arranjo espacial no consórcio algodão herbáceo + caupi + sorgo. Pesquisa Agropecuária Brasileira, Brasília, v. 26, n. 5, p. 715-727, 1991.

CAETANO, L.C.S.; FERREIRA, J.M.; ARAÚJO, M.L. Produtividade de cenoura e alface em sistema de consorciação. Horticultura Brasileira, Brasília, v. 17, n. 2, p. 143-146, 1999.

CARNEIRO, I.F. Competição entre a cultura de repolho (Brassica oleracea var. capitata L.) e a cultura da alface (Lactuca sativa L.) em cultivo misto e em diferentes densidades de população. Piracicaba: ESALQ/USP, 1981. 69 p. (Tese mestrado). MAKISHIMA, N. Cultivo de hortaliças. Brasília: CNPH, 1992. 26 p.
OFORI, F.; STERN, W.R. Cereal-Legume intercropping systems. Advances in Agronomy, New York, v. 41, n. 1, p. 41-90, 1987.

OGBUEHI, C.R.A; ORZOLEK, M.D. Intercropping carrot and sweetcorn in a multiple cropping system. Scientia Horticulturae, Amsterdam, Netherlands, v. 31, n. 1/2, p. 17-24, 1987.

SETÚBAL, J.W.; SILVA, A.M.R. Avaliação do comportamento de alface de verão em condições de calor no município de TeresinaPi. Horticultura Brasileira, Brasília, v. 10, n. 1, p. 69, 1992. (Resumo 127)

VILELA, N.J.; MORELLI, J.B.; MAKISHIMA, N. Impactos socioeconômicos da pesquisa de cenoura no Brasil: 1977-1996. Brasília: EMBRAPACNPH, 1997. 20 p. (EMBRAPA HORTALIÇAS. Documentos, 11). 